\title{
El derecho humano a la participación política
}

\author{
Enrique Bernales Ballesteros*
}

\section{Introducción}

Cuando una democracia alcanza estabilidad y gobernabilidad, los procesos electorales y los derechos que se ejercen para distribuir el poder suelen perder la espectacularidad que los caracteriza para pasar a formar parte de los múltiples escenarios en los que discurre la vida política en una sociedad democrática. Sin embargo, esta actitud despreocupada frente al proceso electoral es posible gracias al respeto y garantía de una serie de derechos que permiten a los participantes de una contienda electoral —electores y elegidos—, ciertas condiciones de equidad y justicia para lograr una participación política efectiva.

Este artículo tratará de brindar algunos aportes al contenido del derecho humano a la participación política y a sus múltiples manifestaciones a partir de una sistematización y evaluación de los tratados internacionales de derechos humanos y de las decisiones de aquellos órganos creados para protegerlos. Aunque con distintos alcances en cuanto a su carácter vinculante, en el derecho internacional se han determinado estándares mínimos respecto al derecho a la participación política que deben o deberían ser respetados. Los sistemas universal y regionales de protección de los derechos humanos cuentan con un plexo de normas que permiten establecer si un Estado respeta el pluralismo político, celebra elecciones libres y justas, y respeta la igualdad de oportunidades para acceder al poder.

Asimismo, esas normas han sido desarrolladas por órganos de protección que individualizan su aplicación, alcances de contenido y garantías. En ese

Doctor en Derecho. Director ejecutivo de la Comisión Andina de Juristas (CAJ) y profesor de la Facultad de Derecho de la Pontificia Universidad Católica del Perú. Trabajo realizado con la colaboración de Luis Enrique Aguilar Cardoso, investigador del Área de Democracia de la CAJ. 
sentido, resulta especialmente importante revisar sus decisiones para poder establecer los avances en la protección de este derecho. Las decisiones de la Corte Interamericana de Derechos Humanos (en adelante, Corte Interamericana), el Comité de Derechos Humanos y el Tribunal Europeo de Derechos Humanos (en adelante, Tribunal Europeo), han establecido criterios de interpretación para los operadores del derecho y argumentos efectivos para los ciudadanos en el momento de alegar la violación del derecho a la participación política.

El proceso de protección y garantía de este derecho se encuentra en una fase intermedia, lo cual origina situaciones de insatisfacción entre quienes promueven su protección. Es necesario tener en cuenta que el derecho internacional contemporáneo se presenta como una disciplina «[...] especialmente problemática, caracterizada por unas acusadas carencias institucionales que motivan incertidumbre y relativismo en el plano normativo, insuficiencias graves en la prevención y sanción de las violaciones y una politización extendida - aunque no absoluta - en la solución de controversias, cuando no la imposibilidad de su arreglo». ${ }^{1}$ Se trata, pues, de un derecho inacabado y muchas veces dependiente de las relaciones de poder entre los sujetos que participan de él.

Esta caracterización del derecho internacional, sus normas, instituciones y sujetos, es especialmente válida en los sistemas de protección de los derechos humanos, donde los Estados soberanos siguen siendo los principales sujetos de derecho internacional, aunque esa soberanía y el poder que esta les otorga disminuyen cada vez más gracias a la tensión dialéctica con principios emergentes como la protección de los derechos humanos y la defensa colectiva de la democracia. ${ }^{2}$

En lo que concierne a la participación política, como bien lo ha indicado el juez García-Sayán, la protección actual que los órganos de derechos humanos le brindan es parte de "[...] un amplio proceso normativo y de afirmación conceptual acerca de los derechos políticos que, por cierto, no se agota en la letra de las disposiciones allí contenidas». ${ }^{3}$ Así, los derechos políticos y su protección actual son una muestra de que la tensión dialéctica mencionada permite proteger cada vez más los derechos humanos. Empero, el proceso de plena garantía de la participación política es delicado, dilatado y aún insuficiente.

\footnotetext{
Pastor Riduejo, José Antonio. Curso de Derecho Internacional público y organizaciones internacionales. Octava edición. Madrid: Tecnos, 2001, p. 21.

2 Respecto a la idea de tensión dialéctica entre los principios de protección de los derechos humanos y soberanía de los Estados, ver: Carrillo Salcedo, Juan Antonio. Soberanía de los Estados y derechos humanos en Derecho Internacional contemporáneo. Segunda edición. Madrid: Tecnos, 2001, p. 186.

3 Corte Interamericana de Derechos Humanos. Caso Yatama. Voto concurrente del juez Diego García-Sayán, párrafo 5.
} 


\section{El derecho a la participación política en los tratados internacionales}

El derecho a la participación política puede ser definido como «[...] la facultad que tienen las personas de intervenir en la vida política de la nación, participar en la formación de la voluntad estatal y en la dirección de la política gubernamental, así como integrar los diversos organismos del Estado». ${ }^{4}$ Por lo tanto, este derecho no se encuentra limitado a lo que tradicionalmente se conoce como política — comprendida como lucha por el poder-, sino que abarca las distintas formas de distribución de poder que permiten incidir en la dirección de lo público en general. ${ }^{5}$

La participación política es un fenómeno complejo y de carácter pluridimensional pues, como dicen Molina Vega y Pérez Barlat, puede tener diversas expresiones caracterizadas por un grado de influencia, precisión en la información, amplitud del resultado, grado de conflicto, nivel de iniciativa personal y grado de cooperación con otros. ${ }^{6}$ Esta pluralidad de dimensiones se concreta en variados modos de participación, desde el tradicional derecho a votar, hasta la actividad particular que un ciudadano puede tener con las autoridades. ${ }^{7}$ No obstante esta pluralidad, en el Derecho Internacional de los Derechos Humanos (en adelante, DIDH), el desarrollo normativo y de las decisiones no representan con exactitud este carácter multimodal del derecho.

$\mathrm{Si}$ bien existen diversas maneras de participar en política, la tendencia actual orienta hacia un complemento de las instituciones de la denominada democracia representativa con aquellas que son propias de la democracia direc$t a$, en tanto que «[...] expresa no solamente un sistema de toma de decisiones, sino un modelo de comportamiento social y político, fundamentado en los principios de pluralismo, la tolerancia, la protección de los derechos y libertades así como en una gran responsabilidad de los ciudadanos en la definición del destino colectivo». ${ }^{8}$ Sin embargo, aún falta saber cómo reaccionará el DIDH frente al fenómeno de la democracia participativa, cuyas especiales características transforman la naturaleza de la participación política.

4 Comisión Andina de Juristas. Protección de los derechos humanos: definiciones operativas. Lima: CAJ, 1997, p. 243.

5 Cuevas García, María Gabriela. «Derechos humanos y participación política». En http:// www.ucab.edu.ve/ucabnuevo/cdh/recursos/anexo2.doc

6 Molina Vega, José Enrique y Carmen Pérez baralt. «Participación política y derechos humanos». En Revista IIDH, n 34-35, San José, 1995, pp. 15-16.

7 Los citados autores mencionan cinco modos de participación política: votación; campaña política (participar como candidato a un cargo público o ser parte de un partido político); actividad comunitaria (trabajo conjunto para solucionar un problema, incluida la actividad de protesta); actividad particular; y ejercicio de cargos públicos de dirección política.

8 Comisión Andina de Juristas. Protección de los derechos humanos: definiciones operativas. Lima: CAJ; p. 244. 
Ese momento no está tan lejano, pues los procesos constitucionales ya están generando nuevas estructuras para la relación entre ciudadanos y el Estado y, por lo tanto, ampliando el contenido de las libertades políticas, como el derecho a la participación. Así, por ejemplo, la Constitución colombiana de 1991 eleva al rango de principio a la democracia participativa y establece nuevas formas de participación, distintas a las tradicionalmente conocidas. ${ }^{9}$ Así, para la Constitución colombiana, la participación en los asuntos públicos

[...] no comprende simplemente la consagración de mecanismos para que los ciudadanos tomen decisiones en referendos o en consultas populares, o para que revoquen el mandato de quienes han sido elegidos, sino que implica adicionalmente que el ciudadano puede participar permanentemente en los procesos decisorios no electorales que incidirán significativamente en el rumbo de su vida. Se busca así fortalecer los canales de representación, democratizarlos y promover un pluralismo más equilibrado y menos desigual. ${ }^{10}$

Mientras tanto, en el DIDH el desarrollo normativo es aún débil y muy probablemente limite la interpretación de sus órganos de protección. Así, en los tratados generales de derechos humanos ${ }^{11}$ se establecen como derechos políticos, con mayor o menor precisión, el derecho de acceso a la función pública, el derecho a participar en la dirección de los asuntos públicos y el derecho al sufragio activo y pasivo. ${ }^{12}$ Sin embargo, existen marcadas diferencias entre la regulación que los sistemas brindan a la participación política y, en algunos casos, importantes insuficiencias.

Veamos, por ejemplo, el Convenio Europeo para la Protección de los Derechos Humanos y Libertades Fundamentales (en adelante, Convenio Europeo). Este tratado no reconoce explícitamente dimensión alguna del derecho a la participación política. Es su Protocolo Adicional (artículo 3) el que reconoce este derecho, aunque como una obligación de los Estados de «[...] organizar, a intervalos razonables, elecciones libres con escrutinio secreto, en condiciones

9 Por ejemplo, véase el artículo 270 de la Constitución de 1991 que establece: «La ley organizará las formas y los sistemas de participación ciudadana que permitan vigilar la gestión pública que se cumpla en los diversos niveles administrativos y sus resultados».

10 Corte Constitucional de Colombia. Sentencia de revisiones constitucionales de proyectos de ley estatutarias $\mathrm{n}^{\circ} \mathrm{C}-180$, del 14 de abril de 1994. En Gaceta de la Corte Constitucional, tomo 4, Bogotá, 1994, p. 451.

11 Nos referimos, en el caso del sistema universal, al Pacto de Derechos Civiles y Políticos; en el caso del sistema interamericano, a la Convención Americana sobre Derechos Humanos; y, en el caso del sistema europeo, al Convenio Europeo para la Protección de los Derechos Humanos y de las Libertades Fundamentales (artículo 3).

12 Declaración Universal de Derechos Humanos (artículo 21); Pacto Internacional de Derechos Civiles y Políticos (artículo 25); Protocolo Adicional al Convenio Europeo de Derechos Humanos (artículo 3); Convención Americana sobre de Derechos Humanos (artículo 23); y Carta Africana de Derechos Humanos y de los Pueblos (artículo 13). 
que garanticen la libre expresión de la opinión en la elección del cuerpo legislativo». Por lo tanto, para Europa, la participación política es el derecho:

- A que sean celebradas elecciones libres y periódicas.

- Al sufragio secreto.

- A que se garantice la libertad de expresión y opinión en los procesos electorales.

- A elegir elecciones para el caso del cuerpo legislativo.

Como vemos, la regulación que el derecho a la participación política recibe en Europa es bastante restrictiva debido a que el Protocolo Adicional no hace referencia al derecho de acceso a cargos públicos. Sin embargo, y por eso mencionamos el caso europeo, esta deficiente regulación no ha detenido la labor interpretativa del Tribunal Europeo y de la extinta Comisión Europea que mediante sus decisiones han logrado ampliar los ámbitos de la participación política. La Comisión Europea ha interpretado de manera extensiva la noción de cuerpo legislativo, señalando que no quiere decir, necesariamente, Parlamento o Congreso nacional, sino que debe interpretarse tal acepción a la luz de la estructura constitucional del Estado de que se trate.

Los órganos de protección del sistema europeo han interpretado que cuerpo legislativo hace referencia a los consejos de las comunidades y regiones de Bélgica, ${ }^{13}$ los parlamentos regionales de Alemania ${ }^{14} \mathrm{y}$ Austria, ${ }^{15} \mathrm{e}$ inclusive al Parlamento Europeo. ${ }^{16}$ Por el contrario, no se ha pronunciado acerca de si pueden considerarse cuerpo legislativo» las asambleas municipales. ${ }^{17}$ Estas decisiones, en mayor o menor medida, han ampliado el derecho a la participación política de los ciudadanos europeos, en tanto que la exigibilidad de participar en un proceso electoral no se ha restringido a la elección de los parlamentos nacionales, sino que actualmente puede ser alegada para otras instancias, y que puede no estar prevista en los ordenamientos internos.

En este desarrollo jurisprudencial resalta la sentencia del Tribunal Europeo referida al Parlamento Europeo, pues el asunto en debate era si acaso el Tribunal podía pronunciarse sobre la naturaleza de un organismo que no es Parte del Convenio Europeo. Sin embargo, en el asunto Matthews contra el Reino Unido, el Tribunal determinó no solo la naturaleza legislativa del Parlamento Europeo, sino que afirmó que "[...] el Convenio no excluye la transferencia de

StedH. Mathieu-Mohin y Clerfayt contra Bélgica, sentencia del 2 de marzo, 1987.

14 Comisión Europea de Derechos Humanos. Petición 27311/95, decisión del 11 de septiembre de 1995.

15 Comisión Europea de Derechos Humanos. Petición 7008/75, decisión del 12 de julio, 1976.

16 Stedh. Matthews contra Reino Unido, sentencia del 18 de febrero, 1999.

17 SteDH. Ahmed y otros contra Reino Unido, sentencia del 2 de septiembre, 1998. 
competencias a organizaciones internacionales siempre que los derechos del Convenio continúen asegurados. Por lo tanto, la responsabilidad de los Estados continúa incluso después de tal transferencia». ${ }^{18}$

La regulación del derecho a la participación política resulta más completa en el caso del Pacto Internacional de Derechos Civiles y Políticos (en adelante, Pacto Internacional) y en el de la Convención Americana sobre Derechos Humanos (en adelante, Convención Americana). En ambos casos identificamos importantes semejanzas entre las dimensiones o expresiones protegidas y la participación política. Ambos tratados reconocen:

- El derecho a participar en la dirección de los asuntos públicos, directamente o por medio de representantes libremente elegidos.

- El derecho a votar (voto activo) y ser elegidos (voto pasivo) en elecciones periódicas, auténticas, realizadas por sufragio universal e igual (voto universal) y que el voto sea secreto, garantizando la libre expresión de la voluntad de los electores.

- El derecho de acceso a las funciones públicas en condiciones generales de igualdad.

Inmediatamente se puede reconocer la amplitud del derecho a la participación política, a diferencia del caso europeo. No obstante, entre ambos tratados existe una diferencia esencial. Mientras el Pacto Internacional señala que no son aceptables las restricciones y las limitaciones que se basen en "[...] raza, color, sexo, idioma, religión, opinión política o de otra índole, origen nacional o social, posición económica, nacimiento o cualquier otra condición social» (artículo 25 del Pacto, en conexión con el artículo 2), la Convención Americana establece que los únicos supuestos en los cuales se pueden establecer limitaciones al ejercicio de participación política son razones de «[...] edad, nacionalidad, residencia, idioma, instrucción, capacidad civil o mental, o condena, por juez competente, en proceso penal» (artículo 23 de la Convención), no siendo aceptables otros criterios.

Esta regulación transforma a la Convención Americana en el instrumento con un contenido más amplio de protección para la participación política, pues mientras que en el caso del Pacto Internacional es posible aplicar una diversidad de criterios para limitar la participación política — siempre que no sean discriminatorios o indebidos-, en el caso de la Convención Americana esa posibilidad se reduce únicamente a siete razones taxativamente establecidas.

Junto al reconocimiento general de estos derechos, existen algunos desarrollos específicos; por ejemplo, en los tratados que buscan abolir distintas formas de discriminación o en los tratados relativos a los derechos de la mujer. Estos

18 StedH. Matthews contra Reino Unido, sentencia del 18 de febrero, 1999; párrafo 32. 
instrumentos internacionales suelen contextualizar aún más el contenido del derecho y, en algunos casos, agregarle nuevas dimensiones. ${ }^{19}$

Así, la Convención sobre la Eliminación de Todas las Formas de Discriminación contra la Mujer ha establecido que los Estados tienen la obligación de adoptar todas las medidas apropiadas para eliminar la discriminación contra la mujer en la vida política y pública y, en particular, garantizarán a las mujeres, en igualdad de condiciones con los hombres, el derecho a:

- Votar en todas las elecciones y referendos públicos y ser elegibles para todos los organismos cuyos miembros sean objeto de elecciones públicas.

- Participar en la formulación de las políticas gubernamentales y en la ejecución de estas, y ocupar cargos públicos y ejercer todas las funciones públicas en todos los planos gubernamentales.

- Participar en organizaciones y en asociaciones no gubernamentales que se ocupen de la vida pública y política del país.

Estas especiales regulaciones merecen un tratamiento riguroso y un desarrollo analítico que no podemos agotar en este texto. Preferimos, en todo caso, evaluar las condiciones que son necesarias para una adecuada participación política. El pleno goce de un derecho, por su carácter indivisible e interdependiente, obliga a evaluar también si los otros derechos se encuentran vigentes. Asimismo, para el caso del pleno respeto de la participación política, otros derechos y algunos elementos institucionales deben ser adecuadamente regulados.

\section{Condiciones para una efectiva vigencia de la participación política}

En primer lugar, para una efectiva participación política se requiere, necesariamente, el respeto del conjunto de derechos humanos pues ellos son indivisibles, en tanto que no existen categorías de derechos, e interdependientes, pues la violación de un derecho genera, en mayor o menor medida, la violación de

19 Convención Internacional sobre la Eliminación de Todas las Formas de Discriminación Racial (artículo 5.c); Convención Internacional sobre la Protección de los Derechos de Todos los Trabajadores Migratorios y de sus Familiares (artículo 42); Convención sobre la Eliminación de Todas las Formas de Discriminación contra la Mujer (artículo 7); Convención sobre los Derechos Políticos de la Mujer (artículos I, II y III); Declaración de las Naciones Unidas sobre la Eliminación de Todas las Formas de Discriminación Racial (artículo 6); Declaración sobre los Derechos de las Personas Pertenecientes a Minorías Nacionales o Étnicas, Religiosas y Lingüísticas (artículos 2 y 3); Convenio no 169 de la Organización Internacional del Trabajo (OIT) sobre Pueblos Indígenas y Tribales (artículo 6); Proclamación de Teherán, Conferencia Internacional de Derechos Humanos de Teherán, 13 de mayo de 1968 (párrafo 5); Declaración y Programa de Acción de Viena, Conferencia Mundial de Derechos Humanos, 14 a 25 de junio de 1993 (I.8, I.18, I.20, II.B.2.27). 
otros derechos. Por tanto, no basta con que el Estado garantice la participación política, sino que a la vez debe garantizar los demás derechos para evitar que el derecho a la participación se vea vulnerado por vía indirecta.

Esta interdependencia ha sido reconocida por los Estados en la Declaración y Programa de Acción de Viena, donde se indica que:

La democracia, el desarrollo y el respeto de los derechos humanos y de las libertades fundamentales son conceptos interdependientes que se refuerzan mutuamente. La democracia se basa en la voluntad del pueblo, libremente expresada, para determinar su propio régimen político, económico, social y cultural, y en su plena participación en todos los aspectos de la vida. [...] La comunidad internacional debe apoyar el fortalecimiento y la promoción de la democracia, el desarrollo y el respeto de los derechos humanos y de las libertades fundamentales en el mundo entero. ${ }^{20}$

La primera conexión se establece entre la participación política y el derecho de los pueblos a la libre determinación. El Comité de Derechos Humanos, de conformidad con el artículo 1, párrafo 1 del Pacto Internacional, ha señalado que:

[...] los pueblos gozan del derecho a determinar libremente su condición política, y del derecho a elegir la forma de su constitución o gobierno. El artículo $25^{\circ}$ trata del derecho de las personas a participar en los procesos de dirección de los asuntos públicos. Como derechos individuales, tales derechos pueden dar lugar a reclamaciones en virtud del primer Protocolo Facultativo. ${ }^{21}$

Asimismo, resulta indispensable que los derechos a la vida, la integridad y la libertad personal sean asegurados, por cuanto es necesario evitar, por ejemplo en épocas electorales, las antiguas prácticas de desapariciones forzadas, hostigamientos, deportaciones, etc., que inicialmente realizaban los regímenes autoritarios contra sus opositores políticos.

No obstante, es cierto que la violación de estos derechos en conexión con la participación política suele tener nuevas manifestaciones. Al respecto, el Comité de Derechos Humanos en el caso Svetik contra Belarús ${ }^{22}$ —al resolver sobre un boicot de las elecciones locales como forma de expresión política-, sostuvo que, a los efectos de proteger este derecho, los Estados Partes del Pacto

20 Asamblea General de las Naciones Unidas. "Declaración y Programa de Acción de Viena», aprobados por la Conferencia Mundial de Derechos Humanos el 25 de junio de 1993, párrafo 18. A/CONF.157/23, del 12 de julio de 1993.

21 Comité de Derechos Humanos. Observación general no 25. Artículo 25 del Pacto Internacional de Derechos Civiles y Políticos (57º período de sesiones, 1996), párrafo 2.

22 Comité de Derechos Humanos. Comunicación no 927/2000. Svetik v. Belarús. En http:// www.unhchr.ch/tbs/doc.nsf/(Symbol)/18a47c57f4693987c1256f0000482f30?Opendo cument. 
Internacional deben prohibir la intimidación o coerción de los votantes mediante una legislación penal de estricta aplicación. En ese sentido, la intimidación y coerción deben diferenciarse de la exhortación a los electores a boicotear una elección, lo cual en principio no se encuentra prohibido.

De otro lado, la participación política requiere del respeto al principio de no discriminación, requisito importante para la realización de cualquier proceso de participación política, a fin de evitar que determinados sectores de la sociedad sean excluidos. Su marginación les impediría dar a conocer sus problemas, plantear sus propuestas y manifestar su posición frente a cualquier medida gubernamental.

$\mathrm{Al}$ respecto, por ejemplo, el Comité de Derechos Humanos considera que forma parte de las obligaciones de los Estados el cerciorarse que «[...] la ley garantice a la mujer los derechos amparados por el artículo 25 en pie de igualdad con el hombre y adoptar medidas eficaces y positivas, incluida las medidas necesarias de discriminación inversa, para promover y asegurar la participación de la mujer en los asuntos públicos y en el ejercicio de cargos públicos». ${ }^{23}$

Similar preocupación plantea el Comité para la Eliminación de Todas las Formas de Discriminación contra la Mujer, pues los informes de los Estados Partes que examina anualmente le permite establecer que:

[...] la mujer está excluida del desempeño de altos cargos en el gobierno, la administración pública, la judicatura y los sistemas judiciales. Pocas veces se nombra a mujeres para desempeñar estos cargos superiores o de influencia y, en tanto que su número tal vez aumente en algunos países a nivel inferior y en cargos que suelen guardar relación con el hogar y la familia, constituyen una reducida minoría en los cargos que entrañan la adopción de decisiones relacionadas con la política o el desarrollo económicos, los asuntos políticos, la defensa, las misiones de mantenimiento de la paz, la solución de conflictos y la interpretación y determinación de normas constitucionales. ${ }^{24}$

La Corte Interamericana también se ha pronunciado en lo relativo al principio de no discriminación y su relación con la participación política. Para la Corte, tal principio «[...] posee un carácter fundamental para la salvaguardia de los derechos humanos tanto en el Derecho Internacional como en el interno; se trata de un principio de derecho imperativo [...]» —es decir, habría ingresado en el dominio del jus cogens —. Por consiguiente, dice la Corte, «[...] los Estados tienen la obligación de no introducir en su ordenamiento jurídico regulaciones discriminatorias, eliminar las regulaciones de carácter discriminatorio,

23 Comité de Derechos Humanos. Observación general no 25. Artículo 25 del Pacto Internacional de Derechos Civiles y Políticos (57º período de sesiones, 1996).

24 Comité para la Eliminación de Todas las Formas de Discriminación contra la Mujer. Observación general $n^{\circ} 23$. Vida política y pública $\left(16^{\circ}\right.$ período de sesiones, 1997), párrafo 30. 
combatir las prácticas de este carácter y establecer normas y otras medidas que reconozcan y aseguren la efectiva igualdad ante la ley de todas las personas». ${ }^{25}$

Para la Corte solo se asegura el derecho a la participación política sin discriminación cuando «[...] el Estado genere las condiciones y mecanismos óptimos los dichos derechos políticos puedan ser ejercidos de forma efectiva, respetando el principio de igualdad y no discriminación». ${ }^{26} \mathrm{La}$ observancia del principio de legalidad, dice la Corte, «[...] exige que el Estado defina de manera precisa, mediante una ley, los requisitos para que los ciudadanos puedan participar en la contienda electoral, y que estipule claramente el procedimiento electoral que antecede a las elecciones (sic)».27

La conclusión de la Corte no podría ser distinta. Según lo establecido en el artículo 23 inciso 2 de la Convención Americana, es posible reglamentar el ejercicio de los derechos y oportunidades políticas reconocidos en su inciso 1, exclusivamente por las razones que este establece en ese inciso. La restricción debe encontrarse prevista en una ley, no ser discriminatoria, basarse en criterios razonables, atender a un propósito útil y oportuno que la torne necesaria para satisfacer un interés público imperativo, y ser proporcional a ese objetivo. Cuando hay varias opciones para alcanzar ese fin, debe escogerse la que restrinja menos el derecho protegido y guarde mayor proporcionalidad con el propósito que se persigue. ${ }^{28}$

Para el ejercicio de la participación política también resulta importante que exista una libre comunicación e intercambio de información e ideas sobre política entre los ciudadanos, los candidatos y los representantes elegidos. Desde esta perspectiva, las libertades de opinión y de expresión son derechos cuyo respeto permite formarse un panorama sobre la política gubernamental, respaldarla o criticarla, y plantear propuestas para mejorarla o para cambiarla.

En ese sentido, hace dos años el Comité de Derechos Humanos tuvo oportunidad de pronunciarse sobre un caso relacionado a la vinculación entre estas libertades y la participación política. Se trata del caso Yong Joo Kang contra

25 Corte Interamericana de Derechos Humanos. Condición jurídica y derechos de los migrantes indocumentados. Opinión consultiva OC-18/03 de 17 de septiembre de 2003. Serie A, nº 18, párrafo 88; Condición jurídica y derechos humanos del niño. Opinión consultiva OC-17/02 de 28 de agosto de 2002. Serie A, no 17, párrafo 44; y Propuesta de modificación a la Constitución Política de Costa Rica relacionada con la naturalización. Opinión consultiva OC-4/84 del 19 de enero de 1984. Serie A, nº 4, párrafo 54.

26 Corte Interamericana de Derechos Humanos. Caso Yatama. Sentencia sobre el fondo del 23 de junio del 2005, párrafo 195

27 Ibíd. párrafo 206.

28 Corte Interamericana de Derechos Humanos. Caso Ricardo Canese. Sentencia de 31 de agosto de 2004. Serie C, no 111, párrafo 96 y 133; Caso Herrera Ulloa. Sentencia de 2 de julio de 2004. Serie C, no 107, párrafo 121 y 123; y La colegiación obligatoria de periodistas (artículos 13 y 29 de la Convención Americana sobre Derechos Humanos). Opinión consultiva OC-5/ 85 del 13 de noviembre de 1985. Serie A, n 5, párrafo 46. 
República de Corea, ${ }^{29}$ donde el Comité sostuvo que la aplicación de un sistema de conversión ideológica a un recluso condenado por espionaje por la distribución de información disponible públicamente violaba su derecho a la libertad de opinión y expresión.

El peticionario, junto con otros conocidos suyos, se oponía al régimen militar del Estado. En 1984, distribuyó panfletos en los que criticaba al régimen y el uso de las fuerzas de seguridad para acosarlo a él y a otros. Luego de ser detenido y mantenido incomunicado 36 días, y presuntamente torturado y maltratado, confesó que era espía de Corea del Norte. Posteriormente, fue juzgado por presuntas violaciones a la Ley de Seguridad Nacional y condenado a cadena perpetua, sobre la base de sus confesiones. Para el momento de la decisión del Comité, el peticionante se encontraba en libertad.

En su fallo, el Comité evaluó el sistema de conversión ideológica - que presuntamente se le habría aplicado estando en prisión en calidad de «delincuente confidente» de los comunistas- Este sistema tenía el propósito de inducir un cambio en la opinión política a través de medidas tales como el confinamiento en solitario por largos períodos para quienes no demostrasen signos de arrepentimiento tras haber cometido delitos que apuntaban a destruir el orden de libertad democrática básica negándolo (Reglamento de 1951 sobre clasificación y tratamiento de condenados). En su denuncia, el peticionario sostuvo que se le mantuvo en confinamiento solitario por trece años por negarse a «cambiar» sus creencias políticas. Argumentaba que la coerción para que cambiara de opinión política y la retención de beneficios — como la posibilidad de obtener la libertad condicional — si no se convertía, equivalían a una violación de su derecho a la libertad de conciencia.

Ante los hechos, el Comité concluyó que el sistema de conversión ideológica violaba los derechos enunciados en los artículos 18 y 19 del Pacto, pues era coercitivo y aplicado en forma discriminatoria con el objetivo de alterar la opinión política de un recluso ofreciéndole incentivos de tratamiento especial en la cárcel y una mayor posibilidad de libertad condicional:

El Comité considera que este sistema, que el Estado Parte no ha demostrado que sea necesario a los efectos de ninguna de las restricciones lícitas enumeradas en los artículos 18 y 19, limita la libertad de expresión y de manifestar las creencias, lo que entraña discriminación por las opiniones políticas, y, por lo tanto, viola el párrafo 1 del artículo 18 y el párrafo 1 del artículo 19, así como también el artículo 26 en ambos casos (párrafo 7.2).

29 Comité de Derechos Humanos. Comunicación no 878/1999. Yong Joo Kang contra República de Corea. En http://www.unhchr.ch/tbs/doc.nsf/(Symbol)/CCPR.C.78.D.878. 1999.Sp? Opendocument. 
Para el desarrollo de las actividades políticas, también son necesarias las libertades de reunión y asociación, pues se convierten en derechos de especial relevancia para desarrollar la dimensión colectiva del derecho a la participación política. La importancia de ambas libertades ha sido reconocida por el Comité de Derechos Humanos pues considera que la participación política «[...] se respalda garantizando la libertad de expresión, reunión y asociación». ${ }^{30}$

En segundo lugar, para que se logre una efectiva participación política no basta con reconocer los derechos humanos mencionados, es importante también que las instituciones encargadas de tutelarlos, como el Poder Judicial, el Ministerio Público, la Defensoría del Pueblo y los tribunales o cortes constitucionales, puedan desarrollar sus funciones sin verse afectadas por clase alguna de interferencia. ${ }^{31}$ Esto implica que se respeten las denominadas garantías institucionales, que según la Corte Constitucional de Colombia pueden ser entendidas como:

[...] la protección constitucional conferida a determinadas instituciones, típicas y por lo tanto necesarias de la organización político-administrativa. La garantía institucional es un límite inclusive para el propio legislador, necesaria en la configuración y regulación de determinadas instituciones; asegurando que no haya ni supresión ni vaciamiento ni desfiguración de la imagen maestra. $^{32}$

La Corte Constitucional hace hincapié en que la garantía institucional no existe sin la previa existencia del Estado, mientras el derecho fundamental existe per se. "Al ser ambos integrados a la Constitución, el derecho fundamental constitucional crea derechos subjetivos de manera inmediata, mientras que de la garantía institucional constitucionalizada los derechos subjetivos solo se desprenden en forma mediata [...]». Sin embargo, su importancia resulta vital, por ejemplo, para salvaguardar la independencia del legislador (inmunidad parlamentaria) o del juez (independencia judicial).

En tercer lugar, debido principalmente a que muchas expresiones de la participación política se traducen en procesos electorales, el Comité de Derechos Humanos ha dispuesto proteger el resultado de las consultas o elecciones populares para que reflejen fielmente la voluntad ciudadana. Según el Comité debe existir, en todo Estado, un sistema electoral «[...] para que supervise el proceso electoral y garantice que se desarrolla en forma justa e imparcial y de

30 Comité de Derechos Humanos. Observación general n 25. Artículo 25 del Pacto Internacional de Derechos Civiles y Políticos (57º período de sesiones, 1996), párrafo 8.

31 Comisión ANDINA de Juristas, ob. cit., p. 247.

32 Corte Constitucional de Colombia. Sentencia sobre la acción de tutela $n^{\circ}$ T-322, del 23 de julio de 1996, p. 16. 
conformidad con disposiciones jurídicas compatibles con el Pacto». ${ }^{33}$ En ese sentido, el Comité de Derechos Humanos ha señalado que un sistema electoral debería: ${ }^{34}$

- Ser compatible con el derecho a la participación política.

- Garantizar el respeto de los resultados de las elecciones y su puesta en práctica.

- Respetar el principio de un voto por persona.

- Otorgar igual valor a todos los votos.

- Delimitar los distritos electorales y señalar el método de asignación de votos que no debe desvirtuar la distribución de los votantes ni comportar discriminación alguna contra ningún grupo, ni tampoco excluir o restringir en forma irrazonable el derecho de los ciudadanos a elegir libremente a sus representantes.

- Crear una junta electoral independiente para que supervise el proceso electoral y garantice su desarrollo en forma justa e imparcial.

En conclusión, la participación política requiere del respeto de los demás derechos inherentes al ser humano, así como de las garantías institucionales que aseguren la independencia y autonomía de los órganos del Estado encargados de tutelarlos. De lo contrario, la vigencia de los derechos humanos en general se pone en cuestión.

El juez Antonio Cançado Trindade nos recuerda con propiedad que la Corte Interamericana, en el ejercicio de su competencia en materia contenciosa, ha resaltado que los Estados Partes tienen el deber de organizar todas las estructuras a través de las cuales se manifiesta el ejercicio del poder del Estado, con la finalidad de prepararlas para asegurar el pleno ejercicio de los derechos humanos. «Es así, agrega, que en el continente americano, gradualmente, se esté formando una jurisprudencia de reconocimiento de los estrechos vínculos entre la democracia y los derechos humanos. Por tanto, derechos humanos y las instituciones democráticas son conceptos indesligables y necesitan existir mutuamente». ${ }^{35}$

Para el continente americano tal aseveración resulta indesligable para los Estados, pues la propia Organización de Estados Americanos tiene como principio

33 Comité de Derechos Humanos. Observación general no 25. Artículo 25 del Pacto Internacional de Derechos Civiles y Políticos (57º período de sesiones, 1996), párrafo 20.

34 Comisión Andina de Juristas, ob. cit., p. 247. Citando a: Comité de Derechos Humanos. Observación general $\mathrm{n}^{\circ} 25$. Artículo 25 del Pacto Internacional de Derechos Civiles y Políticos (57º período de sesiones, 1996), párrafo 20 y 21.

35 Cançado Trindade, Antonio A. Presentación en la ceremonia conmemorativa del segundo aniversario de la adopción de la Carta Democrática Interamericana. San José de Costa Rica, 11 de septiembre, 2003, p. 4. 
rector el respeto de la democracia representativa, sobre la base de lo cual se ha adoptado la Carta Democrática Interamericana, donde puede palparse la íntima relación entre democracia y derechos humanos y se acepta una cláusula democrática que promueve un régimen de defensa colectiva de la democracia y sus componentes.

En el continente europeo, dice Cançado Trindade, el Estatuto del Consejo de Europa condiciona el estatus de miembro a la aceptación de los principios del Estado de Derecho y del goce de los derechos humanos por todas las personas bajo la jurisdicción de cada Estado miembro: ${ }^{36}$

En la práctica, el Consejo de Europa ha condicionado la admisión de miembros a tres requisitos. El primer requisito abarca los siguientes elementos: realización de elecciones pluralistas, en intervalos razonables, por voto secreto y sufragio universal, con los parlamentos gozando de plena autonomía y compuestos de representantes de partidos políticos con libertad de organización y expresión; el segundo requisito comprende los siguientes elementos: el principio de legalidad, el acceso a la justicia, el derecho a una administración correcta de la justicia, las garantías del debido proceso, de audiencias públicas, de la imparcialidad de los jueces y de la proporcionalidad de las penas; y el tercer requisito abarca las obligaciones consagradas en la Convención Europea de Derechos Humanos, sumadas a las de la Carta Social Europea y de la Convención Europea para la Prevención de la Tortura y de Trato o Punición Inhumano o Degradante.

\section{Dimensiones específicas de la participación política}

Revisadas las principales conexiones de la participación política con otros derechos y su dependencia de la existencia y de ciertas garantías institucionales, es momento de revisar las principales expresiones de este derecho reguladas por el DIDH, a partir de las decisiones de los órganos encargados de proteger estos derechos en el ámbito internacional. Se trata, en todo caso, de una primera aproximación desde las principales decisiones de los órganos universales $\mathrm{y}$ regionales.

\subsection{Derecho a participar en la dirección de los asuntos públicos}

El derecho a participar en la dirección de los asuntos públicos es reconocido en los artículos 25 literal a del Pacto Internacional y en el artículo 23 inciso 1 literal a) de la Convención Americana, en términos similares. Se trata de «un

Ibíd. 
concepto amplio que se refiere al ejercicio del poder político» ${ }^{37}$ y abarca «[... $]$ todos los aspectos de la administración pública, así como la formulación y aplicación de políticas internacionales, nacionales, regionales y locales", ${ }^{38} \mathrm{co}-$ rrespondiendo al sistema legal y constitucional del Estado Parte prever las modalidades de tal participación. ${ }^{39}$

Este derecho puede ser ejercido directa o indirectamente, siendo expresiones de su ejercicio directo: a) el ejercer facultades como miembros de órganos legislativos u ocupar cargos ejecutivos, b) decidir cuestiones de interés público mediante consultas populares, y c) asistir a asambleas populares facultadas para adoptar decisiones sobre cuestiones locales o sobre los asuntos de una determinada comunidad..$^{40}$ En todos estos casos, así como en sus manifestaciones indirectas, este derecho puede implicar la realización de críticas u oposición. ${ }^{41}$

No obstante, este derecho también puede ser ejercido indirectamente a través, por ejemplo, de la afiliación a un partido político. Al respecto, el Tribunal Europeo ha podido pronunciarse en el caso Rekvényi contra Hungría ${ }^{42}$ donde tuvo que evaluar la compatibilidad entre el Convenio Europeo y la disposición constitucional húngara que impedía a los militares de carrera, policías y miembros de los servicios civiles de la seguridad nacional la afiliación a un partido político y el ejercicio de actividades políticas. En su decisión, el Tribunal sentenció:

- En relación con la prohibición de afiliarse a un partido político, que no existía violación alguna porque esta respondía a una finalidad legítima, a saber, mantener la neutralidad y la despolitización de la policía, y porque la última frase del artículo 11.2 del $\mathrm{CEDH}$ permite imponer restricciones legítimas a los miembros de las fuerzas armadas, de la policía o de la administración del Estado.

- Respecto del ejercicio de actividades políticas, consideró que las limitaciones no eran excesivas pues respondían a la finalidad legítima de mantener la neutralidad de la policía, y que no violaba el Convenio porque interpretado en

37 Comité de Derechos Humanos. Observación general no 25. Artículo 25 del Pacto Internacional de Derechos Civiles y Políticos (57º período de sesiones, 1996), párrafo 5.

38 Ibíd.

39 Comité de Derechos Humanos. Gran jefe Donall Marshall y otros contra Canadá. Comunicación no 205/1986, párrafo 5.4. En http://www.unhchr.ch/tbs/doc.nsf/(Symbol)/ CCPR.C.43.D.205.1986.Sp?Opendocument

40 Comité de Derechos Humanos. Observación general no 25. Artículo 25 del Pacto Internacional de Derechos Civiles y Políticos (57º período de sesiones, 1996), párrafo 6.

41 Comité de Derechos Humanos. Observaciones finales del Comité de Derechos Humanos, Libyan Arab Jamahiriya, U.N. Doc. CCPR/C/79/Add.45 (1994).

42 StedH. Rekvény v. Hungary, sentencia del 20 de abril, 1999. 
el contexto de otras normas era posible sostener que la prohibición no era absoluta. ${ }^{43}$

En el ámbito americano, este derecho significó un desarrollo en la protección de la participación política. Como lo recuerda el juez García-Sayán, «[...] si bien en los instrumentos primigenios de la OEA, la referencia a la democracia representativa y los derechos políticos casi se agotaba en el derecho de votar y ser elegido, el texto de la Convención ya fue un paso importante en el sentido evolutivo de los derechos políticos abarcando otros componentes importantes como la naturaleza de las elecciones». ${ }^{44}$

En la actualidad, la Corte Interamericana se ha referido a este derecho esencialmente en la participación en la dirección de los asuntos públicos a través de los partidos políticos. Según la Corte, «[...] cualquier requisito para la participación política diseñado para partidos políticos, que no pueda ser cumplido por agrupaciones con diferente organización, es también contrario a los artículos 23 y 24 de la Convención Americana, en la medida en que limita, más allá de lo estrictamente necesario, el alcance pleno de los derechos políticos y se convierte en un impedimento para que los ciudadanos participen efectivamente en la dirección de los asuntos públicos ${ }^{45}$ (las cursivas son nuestras).

Por lo tanto, se puede extraer como conclusión que este derecho no es únicamente individual sino que asegura también la participación de manera agrupada, a través de partidos políticos, y que puede limitarse válidamente la participación de un partido político, siempre que las limitaciones sean acordes a los criterios de razonabilidad y proporcionalidad.

\subsection{Derecho al voto (pasivo y activo)}

Otra expresión de la participación política es el derecho al voto. Este derecho tiene dos dimensiones: una dimensión activa, expresada en el derecho a emitir un voto para elegir a un representante o participar en una consulta — sufragio o voto activo-; y una dimensión pasiva, que brinda al ciudadano el derecho de presentarse como candidato y de ser elegido en los procesos

43 Según los hechos del caso, pese a la restricción, los policías podían votar en elecciones y consultas populares, adherirse a asociaciones, expresar libremente sus opiniones políticas, participar en campañas electorales, presentarse a las elecciones (siendo retirados temporalmente de su puesto durante la campaña electoral y, en su caso, durante el ejercicio de su mandato político), entre otros.

44 Corte Interamericana de Derechos Humanos. Caso Yatama. Sentencia sobre el fondo del 23 de junio de 2005, párrafo 220.

45 Corte Interamericana de Derechos Humanos. Caso Yatama. Sentencia sobre el fondo del 23 de junio de 2005, párrafo 220. 
electorales — sufragio o voto pasivo-. Este derecho ha sido reconocido por el Pacto Internacional (artículo 25, inciso b) y la Convención Americana (artículo 23, inciso b).

Respecto a este derecho, debe tenerse en cuenta que no puede ser ejercido por todas las personas que se encuentran bajo la jurisdicción de un Estado, sino únicamente por aquellas que cumplen con determinados requisitos y que no se encuentran sujetas a alguna restricción en sus derechos políticos. En ese sentido, resulta ser especialmente delicado establecer limitaciones a su ejercicio pues, como ha señalado la Corte Interamericana "[...] el derecho al voto es uno de los elementos esenciales para la existencia de la democracia y una de las formas en que los ciudadanos ejercen el derecho a la participación política. Este derecho implica que los ciudadanos puedan elegir libremente y en condiciones de igualdad a quienes los representarán». ${ }^{46}$

Desde esta perspectiva, corresponde a la legislación de cada país establecer quiénes pueden ejercer el derecho al voto (pasivo o activo). La edad, por ejemplo, generalmente es un criterio usado para limitar la participación a través del voto. También suele serlo la incapacidad mental debidamente verificada o, inclusive, la situación de carcelería. Sin embargo, no todo criterio resulta ser razonable para inhabilitar a una persona en su derecho al voto. Por ejemplo, una discapacidad no puede ser prima face, un criterio para restringirlo. Es el caso de la discapacidad física, respecto de la cual el Comité de Derechos Humanos ha señalado que no es razonable restringir el derecho de voto por motivos de discapacidad física ni imponer requisitos o restricciones relacionados con la capacidad para leer y escribir, el nivel de instrucción o la situación económica. ${ }^{47}$

La Corte Interamericana ha podido pronunciarse sobre el voto pasivo. Para la Corte, «[1]a participación mediante el ejercicio del derecho a ser elegido supone que los ciudadanos puedan postularse como candidatos en condiciones de igualdad y que puedan ocupar los cargos públicos sujetos a elección si logran obtener la cantidad de votos necesarios para ello». ${ }^{48}$ Por eso, en el caso específico de la Comunidad Yatama, la imposición de participar en un proceso electoral a través de un partido político

[...] impuso a los candidatos propuestos por YATAMA una forma de organización ajena a sus usos, costumbres y tradiciones, como requisito para ejercer el

46 Ibíd., párrafo 198.

47 Comité de Derechos Humanos. Observación general no 25. Artículo 25 del Pacto Internacional de Derechos Civiles y Políticos (57º período de sesiones, 1996), párrafo 10.

48 Corte Interamericana de Derechos Humanos. Caso Yatama. Sentencia sobre el fondo del 23 de junio del 2005, párrafo 199. 
derecho a la participación política [...], afectó en forma negativa la participación electoral de dichos candidatos en las elecciones municipales de 2000, por lo que la Corte [...] estima que la limitación constituye una restricción indebida al ejercicio de un derecho político, que implica un límite innecesario al derecho a ser elegido. ${ }^{49}$

El Comité de Derechos Humanos también se ha pronunciado sobre ambas dimensiones del derecho al voto. Respecto del voto activo, el Comité tuvo la oportunidad de decidir la validez de los requisitos de residencia exigidos para participar en una consulta popular sobre la continuación o no del proceso de autodeterminación, la condición de duración de residencia en Nueva Caledonia (Francia), y por otro, para las consultas futuras directamente relacionadas con la opción de la independencia, la consideración de condiciones complementarias relativas a la titularidad del estatuto civil consuetudinario y la presencia en el territorio de los intereses materiales y morales, combinada con el nacimiento del interesado o de sus padres en el territorio. ${ }^{50}$

En aquella decisión el Comité sostuvo que «[...] los criterios expuestos se basan en elementos objetivos de diferenciación entre residentes en su relación con Nueva Caledonia, a saber, las diversas formas de vinculación con ese territorio, específicas o generales, de conformidad con la finalidad y la índole de cada escrutinio. Se plantea, no obstante, la cuestión de determinar si esos criterios tienen o no efectos discriminatorios». ${ }^{51} \mathrm{Al}$ respecto, señaló que los criterios de definición de los cuerpos electorales para las consultas no son discriminatorios, sino que se basan en motivos objetivos de diferenciación razonables y compatibles con las disposiciones del Pacto. ${ }^{52}$

Respecto al voto pasivo, el Comité de Derechos Humanos sostiene que este derecho supone la posibilidad de obtener, mediante procesos electorales, el respaldo de la mayoría de ciudadanos. De acuerdo con el Comité, las personas que reúnan las condiciones exigidas para presentarse a estos procesos electorales, no deberán ser excluidas mediante la imposición de requisitos irrazonables o de carácter discriminatorio, como el nivel de instrucción, el lugar de residencia o la descendencia, o a causa de su afiliación política. ${ }^{53}$

De otro lado, el Comité ha señalado que las razones para la destitución de los titulares de cargos electivos deberán establecerse en disposiciones legales

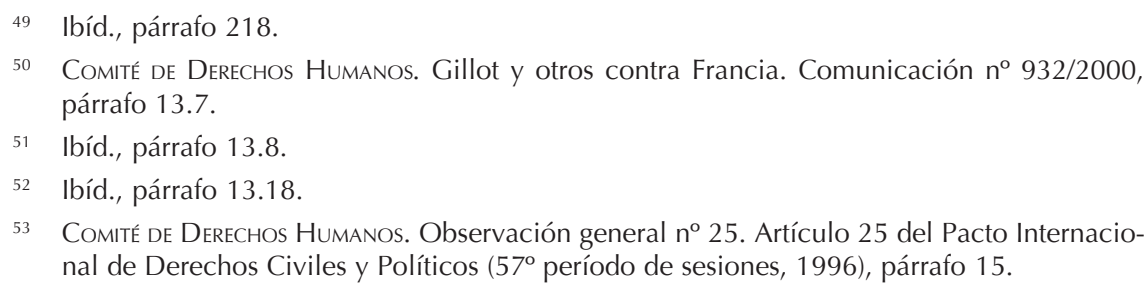


basadas en criterios objetivos y razonables, que comporten procedimientos justos y equitativos. ${ }^{54}$ Como podemos notar, los criterios de protección del Comité no solo alcanzan la posibilidad de acceso a la dirección de asuntos públicos, sino también protegen a los ciudadanos cuando se encuentran ejerciendo un cargo público.

Finalmente, para el Comité:

[e]l derecho de las personas a presentarse a elecciones no deberá limitarse de forma excesiva mediante el requisito de que los candidatos sean miembros de partidos o pertenezcan a determinados partidos. Toda exigencia de que los candidatos cuenten con un mínimo de partidarios [para presentar su candidatura] deberá ser razonable y no constituir un obstáculo a esa candidatura. ${ }^{55}$

Tal vez el desarrollo más interesante del derecho al voto se ha dado en el sistema europeo, donde la decisión más importante hasta la fecha es la sentencia del Tribunal Europeo relativa al asunto Mathieu-Mohin y Clerfayt contra Bélgica (1987). En esta sentencia, el Tribunal desarrolló ampliamente el derecho al sufragio recogido en el artículo 3 del Protocolo Adicional al Convenio Europeo, estableciendo importantes parámetros para su interpretación, incluso sobre la exigencia o no por parte de la $\mathrm{CEDH}$ de un determinado sistema electoral.

En el caso en cuestión, el Tribunal Europeo adoptó los siguientes estándares de interpretación sobre el artículo 3 del Protocolo Adicional: ${ }^{56}$

- El Tribunal ha establecido que el artículo 3 del Protocolo Adicional a la Convención Europea protege el derecho al voto pasivo y activo, a pesar de no estar expresamente reconocido.

- Estableció que el voto pasivo y activo son derechos no absolutos, pues existe un margen para establecer limitaciones que están implícitas.

- Respecto a la obligatoriedad del voto en algunos países, considera que no viola el Convenio cuando los electores tienen la opción de votar en blanco o emitir deliberadamente un voto nulo.

- El artículo 3 exige elecciones «libres» que se celebren «en intervalos razonables», "con votación secreta» $y$ «en condiciones que aseguren la libre expresión de la opinión del pueblo», pero no crea ninguna obligación de establecer un determinado sistema electoral.

El Tribunal Europeo ha sido especialmente cuidadoso respecto a este derecho, tratando de no intervenir sino cuando es necesario. En tal sentido, en el

\footnotetext{
Ibíd., párrafo 20.

55 Ibíd., párrafo 10.

56 SteDH. Mathieu-Mohin and Clerfayt v. Belgium, sentencia del 2 de marzo, 1987, Serie A, no 113.
} 
caso Gitonas and Others versus Greece, el Tribunal sostuvo que no interferirá a menos que las medidas estatales en cuestión no restrinjan estos derechos al «[...] extremo de vaciarlos de su contenido esencial e impedir su eficacia». ${ }^{57}$ Es más, el Tribunal reconoció que la legislación electoral está sujeta a variaciones geográficas y evoluciones temporales ${ }^{8}$ y que todo sistema electoral debe ser evaluado de acuerdo a la evolución política del país en cuestión. Esto explica por qué la Corte Europea ha establecido que ciertas características que resultan inaceptables en el contexto de un sistema determinado pueden justificarse en otros en la medida en que se garantice la libre expresión y opinión de los votantes. ${ }^{59}$

Respecto de las dos dimensiones del voto, el Tribunal Europeo tuvo oportunidad de referirse al sufragio activo en el asunto Matthews contra el Reino Unido ${ }^{60}$ En dicha sentencia, el Tribunal resolvió sobre si el Reino Unido había establecido una restricción indebida al no permitirle a una residente de Gibraltar registrarse como votante en las elecciones al Parlamento Europeo de 1994, alegando que esta colonia no forma parte del Reino Unido sino de los dominios de Su Majestad la Reina. En su sentencia, el Tribunal determinó que el Reino Unido había violado el Convenio Europeo al abstenerse de organizar las elecciones al Parlamento Europeo debido a que se trata de un órgano legislativo y que el Tratado Constitutivo de la Comunidad Europea es aplicable en Gibraltar.

En el caso del derecho a ser elegido (sufragio pasivo), resultan interesantes las decisiones del Tribunal Europeo respecto de la privación del derecho a sufragio a altos funcionarios y a medios de comunicación públicos. Al respecto, han sido reiteradas las decisiones del Tribunal con relación a considerar válidas las restricciones pues resulta necesario resguardar la imparcialidad de los altos funcionarios; de otro modo no sería posible proteger los derechos del elector. Además, para el Tribunal estas restricciones no resultan irrazonables pues las personas afectadas tenían la opción de abandonar temporalmente sus cargos. ${ }^{61}$

También el Tribunal ha podido evaluar las limitaciones por razón del idioma. Así, por ejemplo, en el caso Podkolzina contra Letonia, el Tribunal parece reconocer que la exigencia de acreditar un elevado conocimiento de la única lengua oficial para poder concurrir como candidato a las elecciones parlamentarias supone una injerencia al derecho a elecciones libres (artículo 3, Protocolo 1)

57 Stedh. Gitonas and Others v. Greece, sentencia del 1 de julio, 1997, Reports of Judgments and Decisions 1997-IV, párrafo 39.

58 StedH. Mathieu-Mohin and Clerfayt Case, sentencia del 2 de marzo, 1987, Series A, $n^{\circ} 11$, párrafo 54.

59 Ibíd.

60 Stedh. Matthews v. The United Kingdom, ob. cit.

61 Stedh. Gitonas and others v. Greece, sentencia del 23 de junio de 1997. Asimismo, StedH. Ahmed and others v. The United Kingdom, sentencia del 2 de septiembre de 1998. 
admisible en ciertas circunstancias como las que concurren en la realidad, pero de ninguna manera si son aplicadas arbitrariamente - como sucedió en este caso, donde nueve de veintiún candidatos a un cargo público que poseían el certificado lingüístico requerido fueron sometidos a un segundo examen- $-{ }^{62}$

\subsection{Derecho al acceso a la función pública}

La importancia del derecho de tener acceso a las funciones públicas en condiciones generales de igualdad «[...] radica en que protege el acceso a una forma directa de participación en el diseño, implementación, desarrollo y ejecución de las directrices políticas estatales a través de funciones públicas, tanto para el caso de los funcionarios elegidos por votación popular». ${ }^{63}$ En ese sentido, este derecho se constituye en pieza clave para la organización y funcionamiento de las instituciones públicas.

En Europa, el Convenio Europeo no confiere el derecho a acudir a los tribunales por conflictos relacionados con los nombramientos en ciertos sectores de la administración pública. No obstante, el Tribunal Europeo se pronunció en 1999 sosteniendo que el criterio que debía asumir el Tribunal debe ser funcional y basarse en la naturaleza de los deberes y responsabilidades que el cargo en cuestión entraña. El Tribunal consideró que en cada caso debía determinarse si «[...] el cargo entraña — habida cuenta de la naturaleza y los deberes y responsabilidades a él asociados - una participación directa o indirecta en el ejercicio de facultades conferidas por el derecho público y funciones encaminadas a salvaguardar los intereses generales del Estado o de otras autoridades públicas». ${ }^{64}$

Por su parte, el Comité de Derechos Humanos ha señalado que: a) para garantizar el acceso en condiciones generales de igualdad, resulta indispensable que los criterios y procedimientos para el nombramiento, ascenso, suspensión y destitución sean razonables y objetivos; b) es posible la adopción de medidas positivas; y, c) debe garantizarse, en caso necesario, este derecho frente a cualquier injerencia o presión política y acto de discriminación en el ejercicio de los derechos que les corresponden conforme al apartado c) del artículo $25 .{ }^{65}$

Para los países americanos, la Corte tuvo oportunidad de expresarse sobre este derecho con su sentencia del Caso Yatama. En dicho caso la Corte señaló que:

\footnotetext{
StedH. Podkolzina v. Latvia, sentencia del 9 de abril del 2002.

63 Corte Interamericana de Derechos Humanos. Caso Yatama. Sentencia sobre el fondo del 23 de junio del 2005, párrafo 200.

64 StedH. Pellegrin contra Francia, caso no 28541/1995; sentencia del 8 de diciembre, 1999.

65 Comité de Derechos Humanos. Observación general no 25. Artículo 25 del Pacto Internacional de Derechos Civiles y Políticos (57º período de sesiones, 1996), párrafo 23.
} 
[...] el Estado debe adoptar todas las medidas necesarias para garantizar que los miembros de las comunidades indígenas [...] puedan participar, en condiciones de igualdad, en la toma de decisiones sobre asuntos y políticas que inciden o pueden incidir en sus derechos y en el desarrollo de dichas comunidades, de forma tal que puedan integrarse a las instituciones y órganos estatales y participar de manera directa y proporcional a su población en la dirección de los asuntos públicos, así como hacerlo desde sus propias instituciones y de acuerdo a sus valores, usos, costumbres y formas de organización, siempre que sean compatibles con los derechos humanos consagrados en la Convención. ${ }^{66}$

En este caso, la organización indígena Yatama, cuyo objetivo es la defensa de sus territorios y recursos, se constituyó en partido político para presentarse a las elecciones municipales. Durante el proceso de verificación de las firmas, el Consejo Supremo Electoral excluyó a Yatama de las elecciones.

\subsection{Derecho a constituir organizaciones políticas}

Para finalizar, evaluaremos el desarrollo de una expresión adicional de la participación política no prevista explícitamente en los convenios internacionales. Se trata de la posibilidad de constituir partidos políticos. Al respecto, la Corte Interamericana se pronunció en el caso Yatama, en cuya resolución expresó, entre otras cosas, que: ${ }^{67}$

- La Convención Americana no establece que la única posibilidad para postular a un cargo público sea a través de un partido. Si bien se reconoce la importancia que revisten los partidos políticos como formas esenciales para la democracia, existen otras formas que son inclusive necesarias para favorecer o asegurar la participación política de grupos específicos de la sociedad, tomando en cuenta sus tradiciones y ordenamientos especiales, cuya legitimidad ha sido reconocida e incluso se halla sujeta a la protección explícita del Estado.

- Los partidos y organizaciones políticos deben tener propósitos compatibles con el respeto de los derechos y libertades consagrados en la Convención Americana.

- La participación en los asuntos públicos de organizaciones diversas de los partidos es esencial para garantizar la expresión política legítima y necesaria cuando se trate de grupos de ciudadanos que de otra forma podrían quedar excluidos de esa participación.

66 Corte Interamericana de Derechos Humanos. Caso Yatama. Sentencia sobre el fondo del 23 de junio del 2005; párrafo 225.

${ }^{67}$ Ibíd., párrafo 215-217. 
El Tribunal Europeo también se ha referido a la creación y funcionamiento de los partidos políticos, pero a través de la protección y garantía del derecho a la libre asociación, recogido en el artículo 11 del Convenio Europeo. Al respecto ha afirmado que a pesar de no estar específicamente regulado en el Convenio Europeo, su creación está amparada por el derecho a la asociación basándose en tres argumentos: ${ }^{68}$

a) Una asociación no puede ser privada de la protección por el hecho de que un Estado considere que forma parte de las estructuras constitucionales.

b) El término incluido del artículo 11 del Convenio indica que los sindicatos son uno de los tipos de asociación protegidos por el Convenio - el tratado los menciona específicamente-.

c) Los partidos políticos son una forma de asociación esencial para el propio funcionamiento de la democracia.

Respecto de la disolución de un partido, el Tribunal Europeo ${ }^{69}$ ha señalado que esta es lícita, siempre que legítima —establecida en el Convenio- y, además, debe ser necesaria en una sociedad democrática. En el sentido de este y otros artículos similares, el Tribunal Europeo entiende que una sociedad democrática se caracteriza por el "pluralismo, tolerancia y espíritu de apertura», y que para que una medida sea necesaria, debe responder a una «necesidad social imperiosa» y ser proporcional con el fin legítimo perseguido.

De esta jurisprudencia pueden inducirse los siguientes principios fundamentales: ${ }^{70}$

- El derecho a la libertad de asociación debe interpretarse a la luz del derecho a la libertad de expresión (artículo 10 del CEDH), que no solo protege las informaciones o ideas consideradas inofensivas, sino también a aquellas que ofenden y escandalizan.

68 StedH. United Communist Party of Turkey and others v. Turkey, sentencia del 30 de enero, 1998.

69 STEDH de 30 de enero de 1998, Partido Comunista Unificado de Turquía (TBKP) y otros contra Turquía; STEDH de 25 de mayo de 1998, Partido Socialista (SP) y otros contra Turquía; STEDH de 8 de diciembre de 1999, Partido de la Libertad y la Democracia (IZDEP) y otros contra Turquía; STEDH de 31 de julio de 2001, Partido de la Prosperidad (Refah Partisi, RP) y otros contra Turquía; SETDH de 9 de abril de 2002, Partido del Trabajo del Pueblo (HEP) y otros contra Turquía; STEDH de 10 de diciembre de 2002, Partido de la Democracia (DEP) y otros contra Turquía; STEDH de 13 de febrero de 2003, Partido de la Prosperidad (Refah Partisi, RP) y otros contra Turquía; y STEDH de 12 de noviembre de 2003, Partido Socialista de Turquía (STP) y otros contra Turquía.

70 Sobre la base de Deop Madinabetia, Xabier. «Los derechos políticos en el Convenio Europeo de Derechos Humanos», manuscrito, pp. 8-11. 
- La ilegalización de partidos políticos es una medida extrema y, en consecuencia, las excepciones previstas en el artículo 11.2 deben ser interpretadas de forma restrictiva.

- Los partidos políticos pueden proponer cambios legales y constitucionales siempre que se den dos condiciones: a) que los medios utilizados sean legales y democráticos, y b) que los cambios propuestos sean compatibles con los principios democráticos fundamentales. En consecuencia, un partido que incitase a la violencia o propusiese una política incompatible con una o más reglas de la democracia, no se beneficiaría de la protección del Convenio, sin perjuicio, naturalmente, de que pueda gozar de protección en el derecho estatal.

- Para apreciar si se dan las causas que permiten disolver un partido político, deben tomarse en consideración tanto los estatutos y programas del partido como sus acciones concretas y las posiciones que defiende.

- En lo relativo a la utilización de medios ilícitos, de esta jurisprudencia pueden extraerse tres importantes conclusiones:

- En primer lugar, que la coincidencia total o parcial entre los objetivos de los partidos políticos y los objetivos de grupos armados o terroristas no implica necesariamente una conexión entre los partidos políticos y la violencia.

- En segundo lugar, que la referencia a la integridad territorial debe ser interpretada muy estrictamente y en conexión con los medios propuestos y los derechos ajenos.

- Por último, que la incitación o aprobación de la violencia debe ser clara, no bastando con afirmar que la causa que defienden los terroristas constituye una justa causa.

Hasta aquí se ha tratado de sistematizar y analizar la evolución de un derecho sustancial para la democracia. Derecho muchas veces desacreditado y hasta cuestionado cuando tiene visos de obligatoriedad. Se espera que este trabajo ayude a una mejor comprensión de sus múltiples dimensiones y permita entrar al análisis de los criterios que informan la regulación del derecho a la participación política en el Perú. Los estándares internacionales, como se puede ver, marcan una ruta especial, pro hommine, que debemos seguir. 